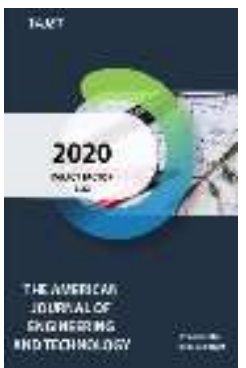

Journal Website: http://usajournalshub.c om/index,php/tajet

Copyright: Original content from this work may be used under the terms of the creative commons attributes 4.0 licence.

\section{Regulation Of The Microclimate Between Finished Products In The Manufacture Of Garments}

\author{
Manzura Abdullajonovna Rizametova \\ Senior Lecturer, Department Of Design, Namangan Engineering Technological Institute, \\ Uzbekistan
}

Dilrabo Khabibillayevna Rayimberdiyeva

Senior Lecturer, Department Of Design And Technology Of Light Industry Products, Namangan Engineering Technological Institute, Uzbekistan

\title{
ABSTRACT
}

This article discusses the types, purpose, shape and structure of clothing, hygienic properties, hygroscopicity, air permeability of the fabric, the dependence of air permeability on wind speed; clothing consists of several layers, the results of observing the average seasonal changes listed. The thickness of the garments of other thicknesses was described in detail.

\section{KEYWORDS}

Human, body, hygienic, thermal conductivity, air permeability, hygroscopicity relative humidity, fabric air humidity, underwear, natural fabrics, fabric, relative humidity, low air, material layer, air permeability, vapor Permeability, household clothing, sportswear, industrial clothing, mechanical properties, working conditions, ceremonial clothing, hospital clothing, microclimate, reliable air, body condition, human mass.

\section{INTRODUCTION}

Clothing is a set of shells on the human body that protects it from the negative effects of the environment: protects from cold and heat, snow, rain and wind, insect bites, claws and teeth of wild animals, blows of spears and swords, bullets and poisonous substances. The concept of clothing includes clothing, shoes, hats, accessories (gloves, scarves, belts, bags, etc.) that are worn directly on 
the body. The main function of clothing is protective (physical and spiritual) and utilitarian-practical functions, because clothing is associated with any human activity and is important for its adaptation to the world around it. Any item in a garment has one or more functions used as an executor. At the same time, clothing also serves an aesthetic function: adorns a person, the concepts of beauty and usefulness in clothing are closely intertwined. Like any other item, clothing is a consumer item.

\section{RESULTS AND DISCUSSION}

To wear clothes is to consume this product. Clothing can be made to order for a specific person, or it can be an industrial product with a circulation of hundreds of thousands of copies. In every case, they captured him, despite obstacles that we cannot even imagine. "In addition, clothing is hygienically protected from environmental pollution, meteorological factors and skin damage" (socially important to hide the human body from the spiritual side). Clothing not only reflects emotions and makes the body beautiful, but also has a positive effect on human health. Clothing should create a comfortable microclimate for the body. A person should dress appropriately for the weather, to prevent overheating of the body, or over-processed clothing can also cause the human body to suffer from various diseases. To do this, the fabric must meet the requirements of hygiene.

The hygienic properties of clothes are mainly characterized by three indicators:

Thermal conductivity

Air permeability

Hygroscopicity

The first indicator is the increase in body heat under the influence of the environment, a characteristic feature of the fabric, the thermal conductivity of the clothing depends on the amount of air inside the fabric. Therefore, clothes made from soft and fluffy fabrics retain heat better. In cold weather, the fabric should have low thermal conductivity, and in hot weather it is advisable to protect it from overheating.

The second indicator - wide, loose summer clothes improve air circulation and normalize air circulation in the body.

The third indicator - hygroscopicity, the fabric must have high air permeability and moisture absorption. Hygroscopicity $(\mathrm{H}, \%)$ is the ability of materials to absorb water vapor from atmospheric air, body surface and keep them under certain conditions. Hygroscopicity is mainly related to the nature of the fibers, the nature of their interaction, the thickness of the tissue. The greatest hygroscopicity is wool fabrics (20\%, etc.), which allow them to maintain high thermal protection properties when wet. Minimum hygroscopicity - is calculated in synthetic fabrics.

Adequate hygroscopicity is a positive feature of the clothing materials used for the inner layers, which should also be useful for a very hard winter fur top. The hygroscopic level of linen fabrics should be at least $7 \%$ at a relative humidity of less than $65 \%$. The thermal properties of the fabric in turn depend on the porosity of the fabric, which is determined by its thermal conductivity, its thickness, the nature of the outer fibers weave and air voids, weak, less thermal conductivity and heat loss diametrically small. The thermal conductivity (fabric) of fabrics characterizes heat resistance.

Air permeability - the ability of the fabric to pass air and moisture, hygienic fabrics adjacent to the skin should be hygroscopic (sweat) and breathe well.

The fabric must be permeable to air and moisture. The underwear must have a high hygroscopicity (moisture absorption) and high air permeability as it touches the fabric.

Underwear fabrics have positive results: they are less worn and have higher air circulation than natural fabrics, they transmit ultraviolet light better. Air permeability (dm3/ m2s) - determines the surface 
area of the fabric, space ventilation and convection, heat return with heat and moisture properties. It is permeable if the holes in the tissue and their amount are the same, especially if they are the same as other things. Water permeability is closely related to the ability of tissue fibers to absorb water. When the space between the tissues is filled with moisture, there is less air. The air permeability of a fabric is characterized by the amount of air at a given pressure across the surface of a unit. The air permeability of home fabrics ranges from 2 to $60,000 \mathrm{dm} 3 / \mathrm{m} 2 \mathrm{~s}$ under a pressure of $9.8 \mathrm{~Pa}(1 \mathrm{~mm}$ $\mathrm{Hg})$. The greater the thickness of the fabric at a wind speed above $4 \mathrm{~m} / \mathrm{s}-7-20 \mathrm{dm} 3 / \mathrm{m} 2 \mathrm{~s}$, the lower the air permeability, the other values are equal.
Air permeability of fabrics largely depends on their structure, density, thickness and moisture. Depending on the level of air permeability, on average, low air permeability with a small (25.1-50 $\mathrm{dm} 3 / \mathrm{m2s}$ ), wind resistance (3.57-25 breathable $\mathrm{dm}_{3} /$ $\mathrm{m} 2 \mathrm{~s}$ ), material layer with (50-115 dm3/ m2s), very high air permeability (125.1-667 dm3/m2s), high (115.1-125.0 $\mathrm{dm} 3 / \mathrm{m} 2 \mathrm{~s}$ ). These factors are taken into account when using fabrics for the production of various garments, including special garments.

The degree of breathability of the fabric, (These factors are taken into account when using fabrics for the production of various clothes, including special ones).

\section{Table 1}

\begin{tabular}{|r|c|c|}
\hline № & Name of indicators & $\begin{array}{l}\text { Air permeability } \\
\left(\mathrm{dm}^{3} / \mathrm{m}^{2} \mathrm{~s}\right)\end{array}$ \\
\hline 1. & On average, a small one & $25,1-50$ \\
\hline 2. & low & $3,57-25$ breathing \\
\hline 3. & Very high air permeability & $125 \cdot 1-667$ \\
\hline 4. & It was high & $115.1-125.0$ \\
\hline
\end{tabular}

The importance of air permeability depends on wind speed.

At wind speeds up to $2 \mathrm{~m} / \mathrm{s}, 7-60 \mathrm{dm} 3 / \mathrm{m} 2 \mathrm{~s}$ the materials used to ensure the air permeability of the product package should be used as the base fabric (when laid under it); $2 \mathrm{~m} / \mathrm{s}$ wind speed 7-20 dm3/m2s materials that provide air permeability of the kit; 


\section{Table 2}

\begin{tabular}{|c|l|c|}
\hline № & $2 \mathrm{~m} / \mathrm{s}$ at wind speeds up to & Indicators $\left(\mathrm{dm}^{3} / \mathrm{m}^{2} \mathrm{~s}\right)$ \\
\hline 1. & $\begin{array}{l}\text { Indicators Air permeability of } \\
\text { the product package }\end{array}$ & $7-60$ \\
\hline 2. & $\begin{array}{l}\text { Materials that provide air } \\
\text { permeability of the kit; }\end{array}$ & $7-20$ \\
\hline
\end{tabular}

\section{MATERIALS THAT PROVIDE AIR PERMEABILITY}

The air permeability of different clothing materials varies over a much wider range. The lowest permeable skin is from 0.001 to $0.1 \mathrm{dm} 3 / \mathrm{mz}$. In contrast, the permeability of cotton and silk fabrics, knitted garments usually exceed $10.0 \mathrm{~cm} 3 / \mathrm{m} 2$, the air permeability of the fabric is studied by a combination that simultaneously enters a particular garment.

\section{AIR PERMEABILITY OF NATURAL FABRICS}

Table 3

\begin{tabular}{|c|l|l|}
\hline № & At wind speeds up to $2 \mathrm{~m} / \mathrm{s}$ & Indicators \\
\hline 1. & $\begin{array}{l}\text { Natural leather (sheep, cattle, } \\
\text { rabbits, etc.) }\end{array}$ & $0,001 \mathrm{from} 0,1 \mathrm{dm}^{3} / \mathrm{m}^{2} \mathrm{~s}$ \\
\hline 2. & Cotton, silk knitwear & $10.0 \mathrm{~cm}^{3} / \mathrm{m}^{2}$ \\
\hline
\end{tabular}

Based on the above table, the vapor permeability of garments ( $\mathrm{g} / \mathrm{m} 2 \mathrm{~s}$ ) is the ability of the fabric to constantly generate water vapor in the garment area.

The release of water vapor from different layers of clothing depends on the air permeability of the fabric. However, vapor permeability and air permeability are not always parallel. For example, some materials (leather) with very low air permeability have the ability to conduct large amounts of water vapor.

Water permeability is the water permeability of materials that fall under pressure or in the form of droplets. Water can be absorbed into the material quickly or slowly, in large or small amounts. Water permeability is a property expressed in terms of water resistance. If we take into account that the moisture then evaporates and receives a very large 
amount of heat, a sharp negative effect of wet clothing is detected.

Based on the above indicators, modern clothing is classified on the basis of the protective function that determines its function. Clothing is divided into three classes according to function:
a. Household clothes;
b. Sportswear;
c. Manufacturing clothing.

The function of household clothing is to protect the human body from the effects of climate.

Sportswear should protect the athlete's body from various injuries and ensure high athletic performance.

Industrial clothing should protect people not only from climatic influences, but also from the effects of production. Clothing for each class is divided into subclasses, types, and subgroups according to function.

The home appliance class is the largest class. It is divided into the following subclasses: 1.1 underwear; 1.2 suits; 1.3 outerwear; 1.4 corset items; 1.5 hats; 1.6 gloves. Each subclass is divided into types. For example, a suit-suit subclass 1.2 is divided into the following types: 1.2.1-jacket; 1.2.2 jacket; 1.2.3 jacket and so on. Age - Sexually, clothing is grouped as follows: men's clothing, women's clothing, children's clothing. Children's clothing, in turn, differs from baby clothes, nursery, preschool, junior school and teen clothes.

Depending on the season and climatic zone, clothing is divided into small groups: Seasonal (winter, spring, summer and autumn), climatic features (tropical, subtropical), influenced by a specific geographic environment (mid-latitude, north, south) and adequate protection from these influences. features of home clothes;

The small weight, due to its mechanical properties, makes the fabric loose and soft, and children's clothing made from selected fabrics protects from the cold in the cold season and protects from overheating in the summer;

There are many types of work clothes and footwear to protect a person who is exposed to occupational hazards, who has a professional appearance in accordance with the working conditions. It is an integral element of personal protective equipment for employees of any manufacturing enterprise. Often clothing is crucial in reducing and protecting the body from the effects of an uncomfortable occupational factor;

Sportswear for various sports In the design of sportswear in a particular sport, taking into account the physiological impact on human health during exercise, the likelihood of mechanical injury and other factors are important, for example, in highspeed sports, properly selected clothing air helps to improve sports results by reducing the displacement of currents. In addition, fabrics for sportswear should be flexible, have good hygroscopicity and air permeability;

The hygiene requirements are high for specially designed clothing from a certain range of fabrics, especially for the military, because the military uniform is his home. The main requirements for the selected fabrics for military uniforms are: fabrics must be highly hygroscopic, have high air permeability, keep warm, dry quickly when wet, wear-resistant, dustproof, easy to wash. should be. Clothing should not be discolored or deformed. Even a soldier wearing completely wet clothing should not weigh more than 7 pounds, otherwise heavy clothing will reduce efficiency. There are everyday and ceremonial military uniforms. There are also seasonal clothing collections. The structure of military uniforms is different and depends on the type of soldiers (sailors, infantry, paratroopers). The ceremonial attire has a variety of details that give the costume a solemnity and sophistication;

Hospital uniforms consisted mainly of pajamas and bathrobes. Such garments should be light, well 
cleaned, easily disinfected, and usually consist of cotton fabrics. The structure and appearance of hospital clothing require further improvement. At the same time it is possible to produce disposable hospital clothes from special paper.

Fabrics for dresses are made of plant, animal and synthetic fibers. In general, clothing consists of several layers, and the average thickness of clothing with a different thickness varies depending on the season.
For example:

a. The thickness of summer clothes is 3.3-3.4 mm, in autumn $5.6-6.0 \mathrm{~mm}$, and in winter from 12 to $26 \mathrm{~mm}$.

b. Weight of men's summer clothes - $2.5-3 \mathrm{~kg}$, winter $-6-7 \mathrm{~kg}$

The average thickness of clothes varies with the season

Table 4

\begin{tabular}{|c|l|c|}
\hline № & \multicolumn{1}{|c|}{ Season } & Thickness (mm) \\
\hline 1 & Summer & $3.3 \mathrm{ch} 3.4$ \\
\hline 2 & Autumn & $5.6 \mathrm{ch} 6.0$ \\
\hline 3 & Winter & $12 \mathrm{ch} 26$ \\
\hline
\end{tabular}

\section{Men's clothing changes depending on the season}

Table 5

\begin{tabular}{|c|l|c|}
\hline № & Season & Weight $(\mathrm{kg})$ \\
\hline 1 & Summer & 2.5 \\
\hline 2 & Winter & $6 \mathrm{ch} 7$ \\
\hline
\end{tabular}

In single-layer products made of thin materials, the internal and external dimensions are almost equal.

In addition to the liner and aura, the multilayer product package also includes intermediate materials. Therefore, the outer dimensions of the garment are designed differently from the inner dimensions to Pt.m to the added value relative to the thickness of the package materials. If we consider the horizontal section of the torso of a dressed man as a circle (Fig. 1a), the approximate value of a single-layer clothing package Pt.m attachment is calculated as follows: Pt.m $=\mathrm{b}$ $R o-R=b=(R o-R-0,5)=0,5$ 
In this case: the central corner of the bow covered with b-dress, rad; -material thickness, $\mathrm{cm}$;

$\mathrm{Ra}$ and Ro - radii of series internal and neutral arcs, $\mathrm{cm}: \mathrm{Rb}=\mathrm{Rv}$
For a multi-layered clothing package, the value of the additive Pt.m, taking into account the thickness of the lining, aura and intermediate materials (Figure 1) will have the following appearance;

$$
\text { Pt.m }=b\left(d_{n}+d_{p r}+d_{\text {u.pr }}\right)+0,5 b d_{o . m}=b\left(d_{n}+d_{p r}+d_{o . m}\right)+0,5 b d_{\text {u.pr }}
$$
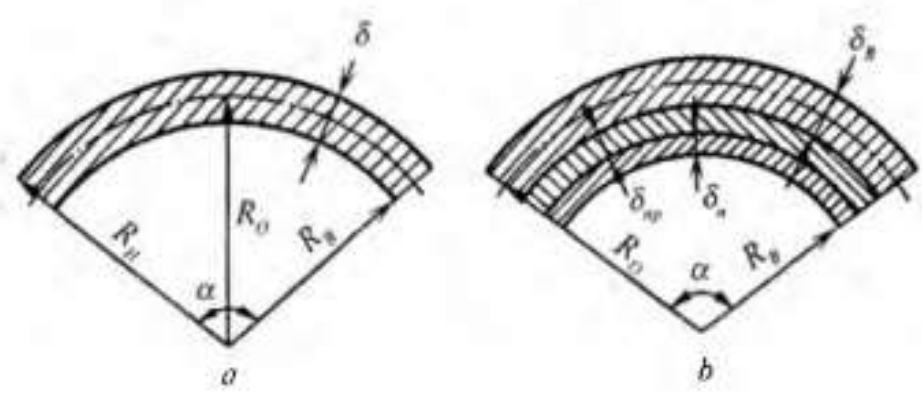

Figure .1 Scheme for calculating the addition to the thickness of the package of materials:

a- single-storey; b-multi-storey

In this: dn - lining thickness, cm; dpr - thickness of the joint, $\mathrm{cm}$; du.pr - thickness of thermal insulation layer, $\mathrm{cm}$; $\mathrm{dn}$ - thickness of base material, $\mathrm{cm}$ (Figures $1-a, b)$

When calculating the addition of material thickness in the design drawing, the central angle $p$ is taken and the appearance of the above formula changes;

Pt.m.=p(dn+dpr+0,5A)+pdu.pr

Here Pt.m.- is an integral part of the composite appendix.

Regardless of the type, purpose, shape and structure of clothing, it must correspond to weather conditions, body condition and work performed in an amount not exceeding $10 \%$ of a person's weight, not to reduce blood circulation, restrict breathing and movement, and does not lead to organ transplantation.

The environment and clothing play a big role in the body's heat exchange process. Provides a microclimate allows the body to be in a normal heat regime under different environmental conditions. A reliable microclimate is a key parameter in choosing a suit, and as a result, a reliable microclimate largely determines a person's thermal health. A reliable microclimate should be understood as a complex description of the physical factors of the air layer that are close to the skin surface and directly affect the physiological state of the person. This is due to the closeness of the body with a particular microeconomic environment, changes in its vital activity affect the body in turn; the thermoregulatory state of the organism depends on reliable microclimate properties. 
Reliable microclimate - characterized by temperature, humidity and carbon dioxide. The temperature of the resistant area varies from $9^{\circ} \mathrm{C}$ to $22{ }^{\circ} \mathrm{C}$, and from 30.5 to $34.6{ }^{\circ} \mathrm{C}$. In temperate climates, the temperature of the sensitive space decreases as it leaves the body, and the high ambient temperature increases as it approaches the body to heat the upper part of the garment with sunlight.

Under average climate station conditions, the relative humidity of reliable air is usually less than the humidity of the surrounding air and increases with increasing air temperature. Thus, for example, the humidity of the air, which is not less than the ambient temperature of $17{ }^{\circ} \mathrm{C}$, is about $60 \%$; when the ambient air temperature rises to $24{ }^{\circ} \mathrm{C}$, the air humidity in the storage area decreases to $40 \%$. When the ambient air temperature rises to $30-32{ }^{\circ} \mathrm{C}$, when a person is actively sweating, the humidity rises to $90-95 \%$.

The air in the safe area contains about 1.5-2.3\% of carbon dioxide, the source of which is the skin. At an ambient temperature of $24-25^{\circ} \mathrm{C}$ per hour, 255 $\mathrm{mg}$ of carbon dioxide is released into storage. On contaminated clothing on the surface of the skin, especially when wet and rising, there is a strong diffusion of sweat and organic matter, which significantly increases the amount of carbon dioxide in the air. If the amount of carbon dioxide in a reliable area does not exceed $0.7 \%$ in clothing made of cotton or satin, the amount of carbon dioxide in tight clothing increases to $0.9 \%$, in warm clothing from $3-4 \%$ to $1.6 \%$ layers.

The properties of clothes mainly depend on the properties of the texture. Depending on the climatic conditions, the thermal conductivity, air permeability should be sufficient, hygroscopicity and moisture content, low gas absorption, should not have disturbing properties. Fabrics should be soft, elastic and strong.
Good air permeability is very important for summer wear. Good absorption of water vapor is a necessary feature of wet fabrics and cannot be absolutely recommended for people working in high humidity environments or working with clean clothes with water (dye shop, sailors, fishermen, etc.).

In the hygienic evaluation of clothing fabrics - their properties of air, water, heat and the ability to retain or transmit ultraviolet light are studied.

The air permeability of the garments is of great importance for reliable area ventilation. It depends on the amount and size of the tissue cavity in the fabric, the weaving properties of the tissue.

Airtight clothing makes it difficult to quickly ventilate a saturated reliable area of water vapor, which disrupts sweat evaporation and causes a person to overheat.

It is very important that the fabrics have sufficient air permeability and are stored in humid conditions, i.e. after wetting with rain or sweating. Basically, clothes prevent air from escaping from the surface of the body, moisture and carbon dioxide accumulate in the inner area, which reduces the protective and normal properties of the skin.

An important indicator of the hygienic properties of fabrics is their dependence on water. Water in the tissues can be in the form of vapors or in the form of liquid droplets. In the first case, they provide information about hygroscopy, in the second case the moisture capacity of the tissue. The currently produced fabric allows you to combine the advantages of natural and synthetic materials. Different assortments of clothing made of composite fibers improve, i.e. reduce, thermal insulation properties, such as electrical charging. Most importantly, it is possible to obtain a fabric with convenient hygienic properties, to improve the heat protection properties of the same type of fiber 
and to change it without other over-processing, giving it an optical property.

Dressing conditions; must correspond to the state of the body and the work performed and not exceed 10 percent of the person's weight; it should not obstruct blood circulation, should not impede breathing and movement, should be easily cleaned of dust and dirt, and should be resistant to washing.

$m=P w^{`}$ ch $10 \%$

$M=$ mass determination

$\mathrm{Pw}=$ weight of a person

$10 \%=$ constant value

Note: The weight of all clothing on the human body should not exceed $10 \%$ of the weight of the human body. For example, if a person weighs $90 \mathrm{~kg}$, the weight of the garment is equal to $10 \%$ of the person's weight, ie $900 \mathrm{mg}$. Exceed to the above conditions can lead to changes in the human body (fatigue, nervousness, weakness).

\section{CONCLUSION}

In conclusion, we can say that the thickness of the garment in the production of the finished product, i.e. increase in body heat under the influence of the environment, specific properties of fabric, hygroscopicity of clothing, absorption of moisture The properties of air in a finished product, such as creating a normal microclimate, are highlighted and widely covered.

\section{REFERENCES}

1. Kamilova Kh.Kh, Khamrayeva N.K. Construction of sewing products. Textbook. Tashkent: “Cholpon”. 2011.
2. Afanasyeva. Hygienic principles of designing clothes for protection from the cold. Moscow: Light Industry, 1977.

3. Hasanbaeva G.K, Chursina V.A. History of costume. Tashkent: Uzbekistan. 2002.

4. Hasanbaeva G. History of textile design. Tashkent: Economics. Finance. 2006. 